\title{
ChemComm
}

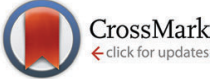

Cite this: Chem. Commun., 2016, 52,6585

Received 4th March 2016 Accepted 18th April 2016

DOI: $10.1039 / \mathrm{c} 6 \mathrm{cc} 01961 \mathrm{~g}$

www.rsc.org/chemcomm

\section{Propentdyopent: the scaffold of a heme metabolite as an electron reservoir in transition metal complexes $\dagger$}

\author{
R. Gautam, T. M. Chang, A. V. Astashkin, K. M. Lincoln and E. Tomat*
}

The dipyrrin-1,9-dione scaffold of heme metabolite propendyopent coordinates late transition metals ( $\mathrm{Co}, \mathrm{Ni}, \mathrm{Cu}$, and $\mathrm{Zn}$ ) forming homoleptic, pseudo-tetrahedral complexes. Electrochemical and spectroscopic studies reveal that the monoanionic, bidentate ligands behave as electron reservoirs as the complexes reversibly host one or two ligand-based radicals.

The degradation of heme in mammalian metabolism begins with the formation of linear tetrapyrrole biliverdin (Chart 1), which is catalysed by heme oxygenase primarily during the processing of senescent erythrocytes. Subsequent enzymatic and non-enzymatic reactions lead to the formation of lowerorder oligopyrroles, ${ }^{1,2}$ containing three or two pyrrole rings, which were first isolated from urinary excretions. The coordination and redox chemistry of these urochrome pigments is far
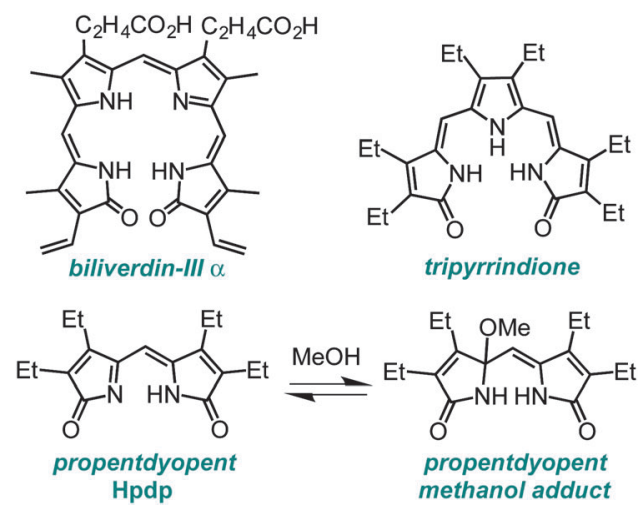

Chart 1 Biliverdin pigment derived from heme $b$ and synthetic analogs of smaller fragments of heme degradation.

University of Arizona, Department of Chemistry and Biochemistry,

1306 E. University Blvd., Tucson AZ 85721, USA. E-mail: tomat@email.arizona.edu $\dagger$ Electronic supplementary information (ESI) available: Synthetic procedures and experimental methods for X-ray diffraction, UV-visible absorption, electrochemistry, and EPR spectroscopic analyses. CCDC 1431584, 1431605, 1434495 and 1434496. For ESI and crystallographic data in CIF or other electronic format see DOI: $10.1039 / \mathrm{c} 6 \mathrm{cc} 01961 \mathrm{~g}$ less established than that of their tetrapyrrolic congeners. We recently reported the first transition metal complexes of the tripyrrin-1,14-dione fragment (Chart 1). ${ }^{3}$ This tridentate planar scaffold serves as a robust platform for $\mathrm{Pd}(\mathrm{II})$ coordination and ligand-based one-electron processes, thus behaving as a redoxactive ligand for the storage of redox equivalents. In general, heme metabolites could offer both the stability of physiological end products and the rich redox chemistry of non-innocent ligands for the engineering of novel redox reactivity. Herein, we examine the metal coordination and redox properties of the propentdyopent system, a heme metabolite and dipyrrolic analog of tripyrrindione and biliverdin.

The unorthodox name propentdyopent refers to the absorption maximum $(525 \mathrm{~nm})$ of the red products (pentdyopents) obtained by reduction of these urinary pigments in alkaline solutions, which was first observed by Stokvis in $1870 .{ }^{4}$ Subsequent studies over a period of five decades established the molecular structure of the propentdyopent family as well as the formation of colorless adducts in the presence of nucleophilic solvents such as water and methanol (Chart 1). ${ }^{5,6}$

Propentdyopent pigments are structurally related to the bidentate ligands of the large family of dipyrrins, ${ }^{7}$ which form dipyrrinato metal complexes employed widely in multiple applications including fluorescent labels for bioimaging (i.e., BODIPY dyes $),{ }^{8}$ coordination polymers, ${ }^{9-11}$ and catalysts. ${ }^{12}$ In spite of this similarity with a versatile family of ligands, the coordination chemistry of propentdyopents remains rather unexplored. Early reports indicated the formation of a zinc complex that was not characterized fully. ${ }^{5,13}$ Interestingly, $\mathrm{Cu}$ (II) and $\mathrm{Co}$ (II) propentdyopent complexes were isolated upon oxidative degradation of copper ${ }^{14}$ and cobalt ${ }^{15}$ complexes of octaethylbilindione, a biliverdin analog. Although propentdyopent complexes have not been detected (and possibly searched for) in biological settings, their formation could therefore arise, at least in principle, from direct metal binding or also from decomposition of complexes of larger pigments. These considerations, along with the possibility to access a new redox-active framework analogous to the tripyrrindione system, motivated the present study. 


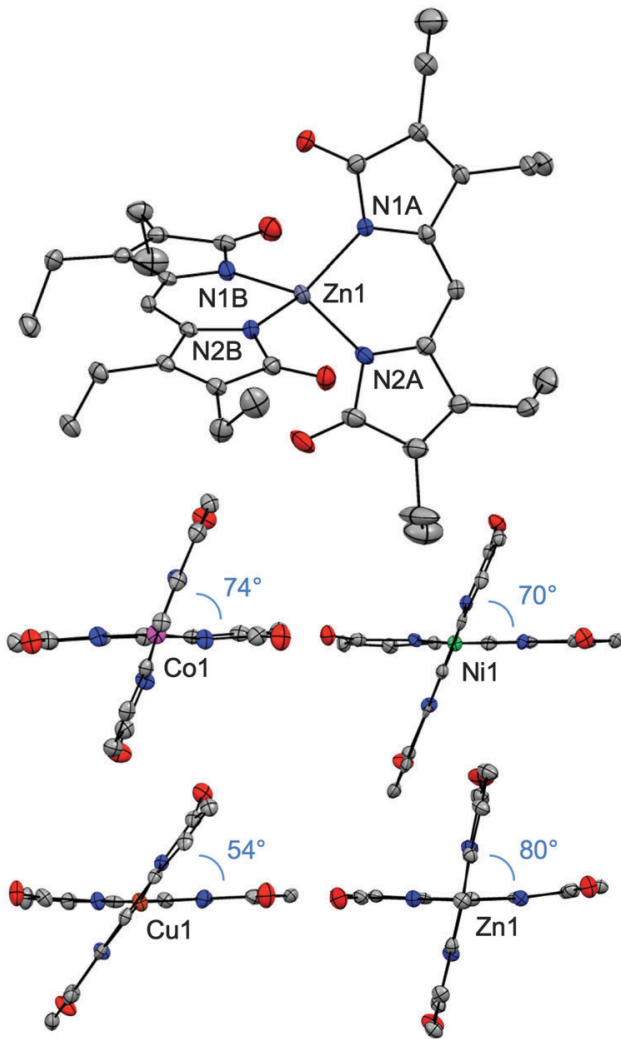

Fig. 1 Crystal structures of homoleptic complexes $\mathrm{Co}(\mathrm{pdp})_{2}, \mathrm{Ni}(\mathrm{pdp})_{2}$, $\mathrm{Cu}(\mathrm{pdp})_{2}$, and $\mathrm{Zn}(\mathrm{pdp})_{2}$ (CCDC: Co, 1434495; Ni, 1434496; Cu, 1431584; $\mathrm{Zn}, 1431605)$. In the views highlighting the dihedral angles between the planes of the ligands, the ethyl substituents have been omitted. Thermal ellipsoids are scaled to the $50 \%$ probability level.

An all-ethyl analog of the naturally occurring propentdyopents (which typically feature methyl, vinyl or propionate substituents) was prepared from the photo-oxygenation of tetraethyldipyrrinone (aka tetraethylpyrromethenone) and isolated as the methanol adduct $\mathrm{Hpdp} \cdot \mathrm{MeOH}$ as previously reported. ${ }^{6,16,17}$ Propentdyopent complexes were prepared in good yields by briefly refluxing (10-30 $\mathrm{min}$ ) methanolic solutions of $\mathrm{Hpdp} \cdot \mathrm{MeOH}$ in the presence of chloride or acetate salts of $\mathrm{Co}(\mathrm{II}), \mathrm{Ni}(\mathrm{II}), \mathrm{Cu}$ (II), and $\mathrm{Zn}$ (II) (see $\mathrm{ESI} \dagger$ for experimental details). The progress of metal coordination was monitored by UV-visible absorption spectroscopy owing to the $\pi-\pi^{*}$ transitions in the visible region that are characteristic of dipyrrin complexes (Fig. S3, ESI $\dagger$ ).

Single crystals were obtained for all four complexes and analysed by X-ray diffractometry (Fig. 1). Each neutral, homoleptic complex features two bidentate propentdyopent ligands in a non-planar geometry typical of 1,9-substituted dipyrrins. ${ }^{7,18,19}$ All complexes are pseudo-tetrahedral, with dihedral angles between the propentdyopent planes being closer to orthogonality for the zinc complex $\left(79.8^{\circ}\right)$ and most distorted for the copper complex $\left(54.2^{\circ}\right)$. These data therefore showed that homoleptic cobalt and copper propentdyopent complexes, which were crystallized previously following degradation of tetrapyrrolic octaethylbilindione complexes, ${ }^{14,15}$ can be obtained directly from reaction with $\mathrm{Hpdp} \cdot \mathrm{MeOH}$. For consistency of comparison across this series of structures of similar resolution, Fig. 1 shows our structures of $\mathrm{Co}(\mathrm{pdp})_{2}$ and $\mathrm{Cu}(\mathrm{pdp})_{2}$ rather than those reported previously (see ESI $\dagger$ for details).

Bond lengths on the ligand frameworks (Table S3, ESI $\dagger$ ) remain comparable across this series (for instance, with $\mathrm{C}-\mathrm{O}$ distances in the (1.209(7)-1.232(6) ̊) range characteristic of carbonyl double bonds) indicating consistency of electronic structure and redox state for the propentdyopent scaffold, which coordinates as a monoanionic bidentate ligand in all cases. In the isolated neutral complexes, all the metal cations therefore maintain their divalent oxidation states and, unlike the tripyrrindione system, ${ }^{3}$ Hpdp does not undergo oxidation upon metal coordination. These considerations were confirmed by spectroscopic methods (vide infra).

The ${ }^{1} \mathrm{H}$ NMR spectrum of diamagnetic complex $\mathrm{Zn}(\mathrm{pdp})_{2}$ exhibits a single set of resonances for the pdp ${ }^{-}$ligands (Fig. S1, ESI $\dagger$ ), thus indicating that $D_{2}$ symmetry is maintained in solution at room temperature. Similarly, only five ligand resonances are observed in the ${ }^{1} \mathrm{H}$ NMR spectrum (Fig. S2, ESI $\dagger$ ) of $\mathrm{Ni}(\operatorname{pdp})_{2}$, a pseudo-tetrahedral $d^{8}$ species $(S=1)$. As observed for other paramagnetic Ni(II) complexes, ${ }^{20}$ this spectrum presents fairly sharp peaks over a relatively narrow spectral window $(70 \mathrm{ppm})$, and the resonances for the meso-type protons are strongly shifted upfield (by $59 \mathrm{ppm}$ ) relative to those of the corresponding protons in $\mathrm{Zn}(\mathrm{pdp})_{2}$.

The continuous-wave (CW) EPR spectrum of Co(pdp) (Fig. S7, ESI $\dagger$ ) recorded at $10 \mathrm{~K}$ presents a broad signal with turning points at $\left(g_{\perp}, g_{\|}\right) \approx(4.5,2.01)$ that are characteristic of a Co(II) center in tetrahedral crystal field $(S=3 / 2)$. The EPR data also confirmed a divalent oxidation state for the copper center in $\mathrm{Cu}(\mathrm{pdp})_{2}$ (Fig. S8 and S9, ESI $\dagger$ ). For both complexes, the lack of hyperfine structure from the central ion nucleus $(I=3 / 2$ and $7 / 2$ for ${ }^{63,65} \mathrm{Cu}$ and ${ }^{59} \mathrm{Co}$, respectively) in the spectra of samples in frozen glassy solutions indicates structural disorder likely related to a variation of the $\mathrm{N}-$ metal- $\mathrm{N}$ bond angle for each of the $\mathrm{pdp}^{-}$ligands and the dihedral angle between the ligand planes. In liquid solutions at room temperature, these structural variations are dynamic and rapid within the EPR timescale, which results in exchange narrowing and a resolved hyperfine structure for the $\mathrm{Cu}$ (II) complex (Fig. S9, ESI $\dagger$ ). The EPR signal from the Co(II) complex is not observed at room temperature because of very short magnetic relaxation times.

All structural and spectroscopic data confirmed a divalent oxidation state for the metal centers in the isolated propentdyopent complexes. Their redox behaviour was then investigated by electrochemical methods (Fig. 2). The cathodic sweep in cyclic voltammograms collected in $\mathrm{CH}_{2} \mathrm{Cl}_{2}$ presents two quasi-reversible one-electron events at half-wave potentials lower than $-1.0 \mathrm{~V} v s$. Fc/Fc ${ }^{+}$(Table S5, ESI $\dagger$ ). These processes, which were previously documented (but not assigned) for cobalt propentdyopent complexes, ${ }^{15}$ are consistent across this series of complexes including the redox-inactive $d^{10} \mathrm{Zn}$ (II) cation and are therefore attributed to ligand-based reduction events. The small difference in half-potentials $(180-260 \mathrm{mV})$ is ascribed to solvation energy effects for the two redox pairs 


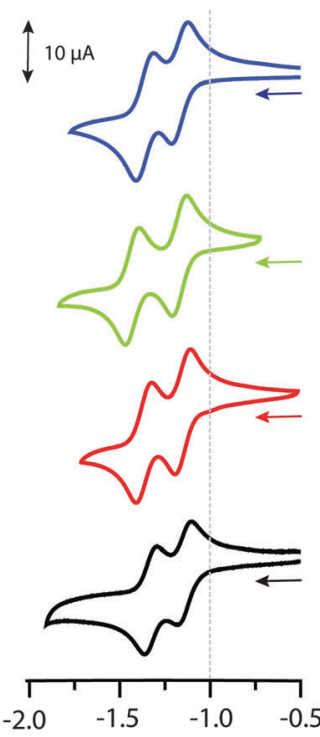

( $\mathrm{V})$

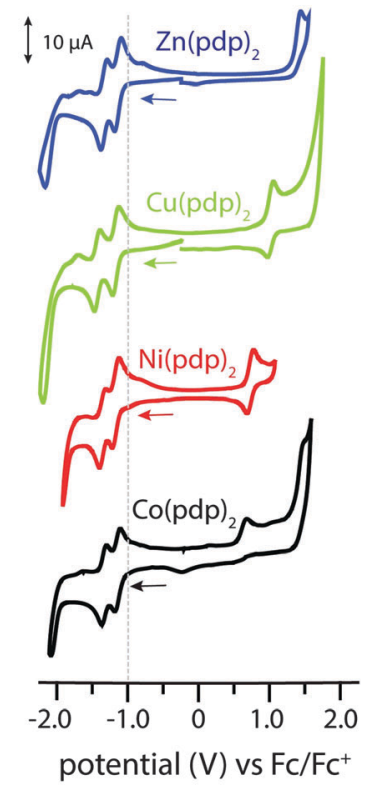

potential (V) vs Fc/Fc
Fig. 2 Cyclic voltammograms of $\mathrm{Co}(\mathrm{pdp})_{2}, \mathrm{Ni}(\mathrm{pdp})_{2}, \mathrm{Cu}(\mathrm{pdp})_{2}$, and $\mathrm{Zn}(\mathrm{pdp})_{2}$ at a glassy carbon electrode in $\mathrm{CH}_{2} \mathrm{Cl}_{2}$ with $\left(n-\mathrm{Bu}_{4} \mathrm{~N}\right)\left(\mathrm{PF}_{6}\right)$ as a supporting electrolyte. Data collected at a $100 \mathrm{mV} \mathrm{s}^{-1}$ scan rate using a $\mathrm{Ag} / \mathrm{AgCl}$ quasireference electrode and a platinum wire auxiliary electrode.

(neutral/monoanionic vs. monoanionic/dianionic species) rather than to delocalization of the first reducing equivalent on both propentdyopent ligands. ${ }^{21}$ As previously noted for the sequential reduction of homoleptic zinc complexes of pyridine2,6-diimine ${ }^{22}$ and formazanate ${ }^{23}$ ligands, the cathodic waves are thus assigned to localized ligand-based reductions forming $\left[\mathrm{Zn}\left(\mathrm{pdp} \mathbf{p}^{\bullet}\right)(\mathrm{pdp})\right]^{-}$and then $\left[\mathrm{Zn}\left(\mathrm{pdp}^{\bullet}\right)_{2}\right]^{2-}$ in the case of the zinc species. In addition, the voltammograms of the complexes of redox-active cations $\mathrm{Cu}$ (II) and $\mathrm{Ni}$ (II) exhibit one-electron, quasi-reversible oxidative processes, presumably of metalbased character, at 0.93 and $0.74 \mathrm{~V}$, respectively. The $\mathrm{Co}(\mathrm{II})$ species presents an irreversible oxidative event at similarly positive potential. Collectively, these electrochemical observations support the notion of bidentate propendyopent ligands serving as electron reservoirs and prompt further characterization of the reduced species. For spectroelectrochemical and EPR spectroscopic investigations, the zinc complex was selected because of its sharp UV-visible absorption bands and because of its lack of metal-based electronic spins.

As determined by spectroelectrochemical methods, the one-electron reduction of $\mathrm{Zn}(\mathrm{pdp})_{2}$ is accompanied by a decrease of the main absorption bands (361 and $491 \mathrm{~nm}$ ) and by the appearance of a new $\pi-\pi^{*}$ transition at $427 \mathrm{~nm}$ (Fig. 3, top panel), which doubles in intensity upon formation of the two-electron reduction product (Fig. 3, bottom panel). The observed additivity of this band (and of the near-IR bands, vide infra) is consistent with two separate one-electron processes occurring on each ligand of the homoleptic complex, ${ }^{22,24}$ and sequential formation of $\left[\mathrm{Zn}\left(\mathrm{pdp}^{\bullet}\right)(\mathrm{pdp})\right]^{-}$and $\left[\mathrm{Zn}\left(\mathrm{pdp}^{\bullet}\right)_{2}\right]^{2-}$ with little or negligible interligand delocalization. In addition, the first reduction causes the appearance of two near-IR bands $(670$ and $740 \mathrm{~nm})$, which are increased in intensity and slightly

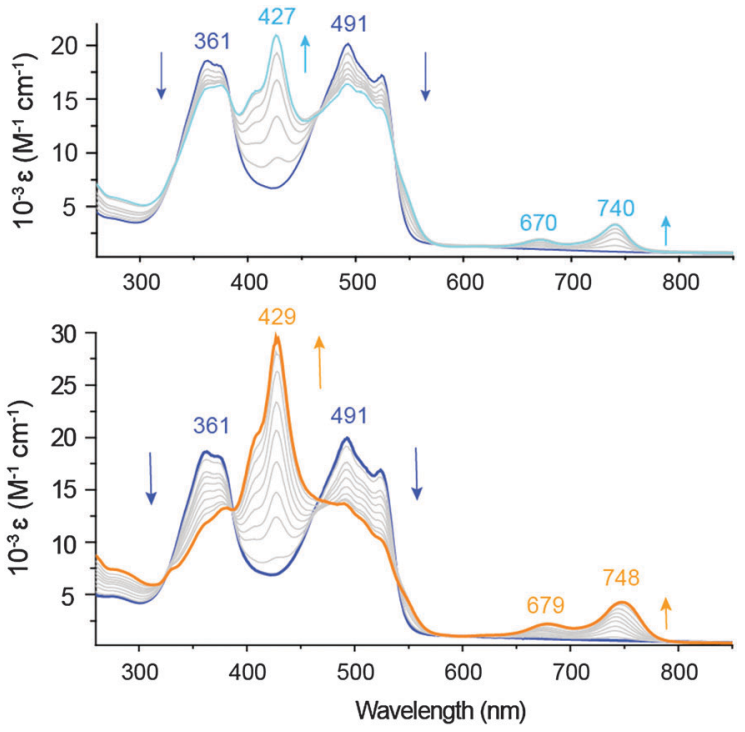

Fig. 3 UV-visible absorption spectral changes observed upon reduction of $\mathrm{Zn}(\mathrm{pdp})_{2}\left(67 \mu \mathrm{M}, \mathrm{DMF}, 0.1 \mathrm{M}\left[\mathrm{NBu}_{4}\right]\left[\mathrm{PF}_{6}\right]\right)$ by controlled potential electrolysis at $-1.2 \mathrm{~V}(200 \mathrm{~s})$ to give $\left[\mathrm{Zn}\left(\mathrm{pdp} \mathrm{p}^{\bullet}\right)(\mathrm{pdp})\right]^{-}$(top panel) and at $-1.8 \mathrm{~V}(400 \mathrm{~s})$ to give $\left[\mathrm{Zn}(\mathrm{pdp})_{2}\right]^{2-}$ (bottom panel).

red-shifted (679 and $748 \mathrm{~nm}$ ) by the second reduction. These low-energy bands are typical of ligand-based $\pi$ radicals in oligopyrroles including tripyrrindione, ${ }^{3}$ corrole $,{ }^{25} 2,2^{\prime}$-bidipyrrin ${ }^{26}$ and bis(phenolate)-dipyrrin. ${ }^{27}$ Confirming the reversible storage of reducing equivalents, exposure to air (over a period of $4 \mathrm{~min}$ ) or application of an oxidizing potential yield over $95 \%$ of the parent complex (Fig. S6, ESI $\dagger$ ).

Both the one-electron and the two-electron reduction products of $\mathrm{Zn}(\mathrm{pdp})_{2}$ could be accessed by chemical reduction and detected by EPR spectroscopy. Following addition of a sub-equimolar amount of sodium amalgam ( 0.8 equiv. $\mathrm{Na}, 4 \mathrm{~h}$ ) to a solution of $\mathrm{Zn}(\mathrm{pdp})_{2}$ in THF at room temperature, the EPR spectrum

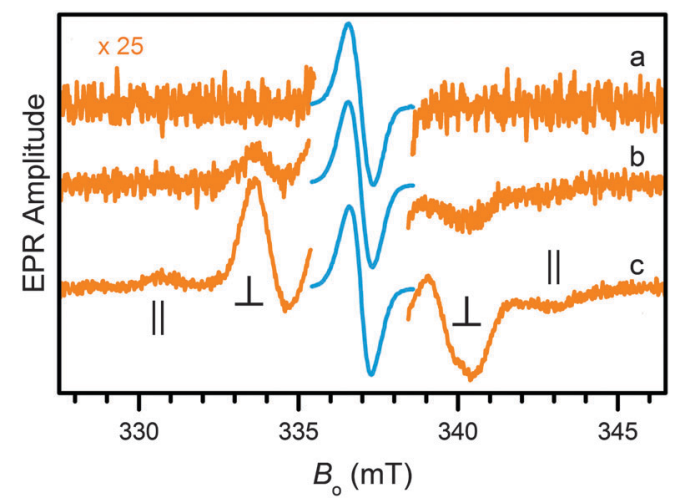

Fig. 4 EPR spectra obtained upon reduction of $\mathrm{Zn}(\mathrm{pdp})_{2}(0.4-0.6 \mathrm{mM}$, THF) with $\mathrm{Na}(\mathrm{Hg})$ and showing formation of an organic radical in subequimolar conditions (trace a, 0.8 equiv. $\mathrm{Na}, 4 \mathrm{~h}$ ) and appearance of increasing amounts of a diradical species in the presence of excess reductant (traces b and c, 3.8 equiv. $\mathrm{Na}, 2.1$ and $3.3 \mathrm{~h}$, respectively). The spectra were normalized to the same amplitude of the central line to allow for comparison of the diradical signals (shown in orange). Experimental conditions: microwave frequency, $9.448 \mathrm{GHz}$; microwave power, $2 \mathrm{~mW}$; field modulation amplitude, $0.6 \mathrm{mT}$; temperature, $77 \mathrm{~K}$. 
(trace a, Fig. 4) of the reaction mixture presents a narrow line $(0.76 \mathrm{mT})$ at $B_{\mathrm{o}}=336.9 \mathrm{mT}(g=2.003)$ as expected for $\left[\mathrm{Zn}\left(\mathrm{pdp}^{\bullet}\right)(\mathrm{pdp})\right]^{-}$, a one-electron reduction product featuring a delocalized ligand-based organic radical $(S=1 / 2)$. In the presence of excess reductant (3.8 equiv. $\mathrm{Na}$ ), the spectrum of a triplet species $(S=1)$ is clearly seen under a larger magnification (trace b, 2.1 h, Fig. 4). The signal increases in amplitude as the reaction progresses and presumably more reductant becomes available in the heterogeneous mixture (trace c, 3.3 h, Fig. 4). This spectrum results from a diradical species with a splitting of $12.5 \mathrm{mT}$ between the $\|$ features. The observed dipole interaction is consistent with diradical species $\left[\mathrm{Zn}\left(\mathrm{pdp}^{\bullet}\right)_{2}\right]^{2-}$ featuring two unpaired electrons, each delocalized on one of the reduced propentdyopent ligands.

In summary, our data show that the propentdyopent scaffold of urinary pigments and heme metabolites serves as a bidentate monoanionic ligand in pseudo-tetrahedral $\mathrm{Co}(\mathrm{II})$, $\mathrm{Ni}(\mathrm{II}), \mathrm{Cu}(\mathrm{II})$, and $\mathrm{Zn}$ (II) complexes. Notably, electrochemical and spectroscopic studies revealed two quasi-reversible reduction processes of ligand-based character leading to formation of paramagnetic anions $\left[\mathrm{Zn}\left(\mathrm{pdp}^{\bullet}\right)(\mathrm{pdp})\right]^{-}$and $\left[\mathrm{Zn}\left(\mathrm{pdp}^{\bullet}\right)_{2}\right]^{2-}$ in the case of $\mathrm{Zn}(\mathrm{pdp})_{2}$. A rich ligand-based redox chemistry is not uncommon in metal complexes of oligopyrroles, which typically present frontier orbitals of predominantly ligand character. The electron-rich $\pi$ system of dipyrrinato ligands, however, is often implicated in one-electron oxidative processes. ${ }^{19,28,29}$ In contrast, in homoleptic propentdyopent complexes, we demonstrated that electron-rich dipyrrolic platforms can reversibly undergo reduction and thereby serve as electron reservoirs for the storage of two reducing equivalents. These biologically occurring dipyrroles therefore extend the chemistry of dipyrrins and offer ligand-based reactivity of potential relevance to their chemistry in biological settings and to synthetic and catalytic applications.

We gratefully acknowledge Drs Jonathan Loughrey and Sue Roberts for assistance with initial electrochemical measurements and analysis of X-ray diffraction data, respectively. This work was supported by the University of Arizona and by the National Science Foundation (CAREER grant 1454047 to E. T.).

\section{Notes and references}

\$ At longer reaction times, both the central line and the dipolar features gradually change, indicating degradation through ligand dissociation and/or reactivity of the reduction products. These effects occur faster with larger amounts of reductant; however, the initial products are stable for about $4 \mathrm{~h}$ at room temperature in the presence of 3.8 equiv. of sodium under an inert atmosphere.
1 H. Falk, The Chemistry of Linear Oligopyrroles and Bile Pigments, Springer-Verlag, Wien, 1989.

2 M. Broring, in Handbook of Porphyrin Science, ed. K. M. Kadish, K. M. Smith and R. Guilard, World Scientific, Singapore, 2010, vol. 8, ch. 41, p. 343.

3 R. Gautam, J. J. Loughrey, A. V. Astashkin, J. Shearer and E. Tomat, Angew. Chem., Int. Ed., 2015, 14894.

4 H. Fischer and H. F. von Dobeneck, Hoppe-Seyler's Z. Physiol. Chem., 1940, 263, 125.

5 R. Bonnett, M. J. Dimsdale and G. F. Stephenson, J. Chem. Soc., Perkin Trans. 1, 1987, 439.

6 R. Bonnett and S. Ioannou, J. Chem. Soc., Chem. Commun., 1986, 213.

7 T. E. Wood and A. Thompson, Chem. Rev., 2007, 107, 1831.

8 T. Kowada, H. Maeda and K. Kikuchi, Chem. Soc. Rev., 2015, 44, 4953.

9 R. Sakamoto, K. Hoshiko, Q. Liu, T. Yagi, T. Nagayama, S. Kusaka, M. Tsuchiya, Y. Kitagawa, W.-Y. Wong and H. Nishihara, Nat. Commun., 2015, 6, 6713.

10 R. Matsuoka, R. Toyoda, R. Sakamoto, M. Tsuchiya, K. Hoshiko, T. Nagayama, Y. Nonoguchi, K. Sugimoto, E. Nishibori, T. Kawai and H. Nishihara, Chem. Sci., 2015, 6, 2853.

11 J. R. Stork, V. S. Thoi and S. M. Cohen, Inorg. Chem., 2007, 46, 11213.

12 E. T. Hennessy, R. Y. Liu, D. A. Iovan, R. A. Duncan and T. A. Betley, Chem. Sci., 2014, 5, 1526.

13 H. von Dobeneck, Hoppe-Seyler's Z. Physiol. Chem., 1941, 269, 268.

14 A. L. Balch, M. Mazzanti, B. C. Noll and M. M. Olmstead, J. Am. Chem. Soc., 1993, 115, 12206.

15 R. Koerner, M. M. Olmstead, P. M. Van Calcar, K. Winkler and A. L. Balch, Inorg. Chem., 1998, 37, 982.

16 R. Bonnett, D. G. Buckley and D. Hamzetash, J. Chem. Soc., Perkin Trans. 1, 1981, 322.

17 R. Bonnett, S. Ioannou and F. J. Swanson, J. Chem. Soc., Perkin Trans. 1, 1989, 711.

18 Q. Miao, J.-Y. Shin, B. O. Patrick and D. Dolphin, Chem. Commun., 2009, 2541.

19 R. Toyoda, M. Tsuchiya, R. Sakamoto, R. Matsuoka, K.-H. Wu, Y. Hattori and H. Nishihara, Dalton Trans., 2015, 44, 15103.

20 A. Sanchez-Mendez, J. M. Benito, E. de Jesus, F. J. de la Mata, J. C. Flores, R. Gomez and P. Gomez-Sal, Dalton Trans., 2006, 5379.

21 P. Zanello, C. Nervi and F. Fabrizi de Biani, Inorganic Electrochemistry: Theory, Practice and Application, RSC, Cambridge, 2011.

22 B. de Bruin, E. Bill, E. Bothe, T. Weyhermuller and K. Wieghardt, Inorg. Chem., 2000, 39, 2936.

23 M.-C. Chang, T. Dann, D. P. Day, M. Lutz, G. G. Wildgoose and E. Otten, Angew. Chem., Int. Ed., 2014, 53, 4118.

24 M. Orio, C. Philouze, O. Jarjayes, F. Neese and F. Thomas, Inorg. Chem., 2010, 49, 646.

25 P. Schweyen, K. Brandhorst, R. Wicht, B. Wolfram and M. Broring, Angew. Chem., Int. Ed., 2015, 54, 8213.

26 M. Broring, C. D. Brandt, J. Bley-Escrich and J. P. Gisselbrecht, Eur. J. Inorg. Chem., 2002, 910.

27 A. Kochem, L. Chiang, B. Baptiste, C. Philouze, N. Leconte, O. Jarjayes, T. Storr and F. Thomas, Chem. - Eur. J., 2012, 18, 14590.

28 E. R. King and T. A. Betley, J. Am. Chem. Soc., 2009, 131, 14374.

29 K. Servaty, E. Cauet, F. Thomas, J. Lambermont, P. Gerbaux, J. De Winter, M. Ovaere, L. Volker, N. Vaeck, L. Van Meervelt, W. Dehaen, C. Moucheron and A. Kirsch-De Mesmaeker, Dalton Trans., 2013, 42, 14188. 